\title{
Smoke injection heights from agricultural burning in Eastern Europe as seen by CALIPSO
}

\author{
V. Amiridis ${ }^{1}$, E. Giannakaki ${ }^{2}$, D. S. Balis ${ }^{2}$, E. Gerasopoulos ${ }^{3}$, I. Pytharoulis ${ }^{4}$, P. Zanis ${ }^{4}$, S. Kazadzis ${ }^{3}$, D. Melas ${ }^{2}$, and \\ C. Zerefos ${ }^{5}$ \\ ${ }^{1}$ Institute for Space Applications and Remote Sensing, National Observatory of Athens, Athens, 15236, Greece \\ ${ }^{2}$ Laboratory of Atmospheric Physics, Aristotle University of Thessaloniki, Thessaloniki, Greece \\ ${ }^{3}$ Institute of Environmental Research and Sustainable Development, National Observatory of Athens, Athens, 15236, Greece \\ ${ }^{4}$ Department of Meteorology and Climatology, Aristotle University of Thessaloniki, Thessaloniki, Greece \\ ${ }^{5}$ Laboratory of Climatology, University of Athens, Athens, Greece
}

Received: 15 July 2010 - Published in Atmos. Chem. Phys. Discuss.: 16 August 2010

Revised: 24 November 2010 - Accepted: 30 November 2010 - Published: 7 December 2010

\begin{abstract}
High frequency of agricultural fires is observed every year during the summer months over SW Russia and Eastern Europe. This study investigates the initial injection height of aerosol generated by the fires over these regions during the biomass burning season, which determines the potential for long-range transport of the smoke. This information is critical for aerosol transport modeling, as it determines the smoke plume evolution. The study focuses on the period 2006-2008, and is based on observations made by the CALIOP instrument on board the NASA CALIPSO satellite. MODIS data are synergistically used for the detection of the fires and the characterization of their intensity. CALIPSO aerosol vertical distributions generated by the active fires are analyzed to investigate the aerosol top height which is considered dependent on the heat generated by the fires and can be associated with the initial injection height. Aerosol top heights of the vertically homogenous smoke layers are found to range between 1.6 and $5.9 \mathrm{~km}$. Smoke injection heights from CALIPSO are compared with mixing layer heights taken by the European Centre for Mediumrange Weather Forecast (ECMWF), to investigate the direct injection of smoke particles into the free troposphere. Our results indicate that the aerosol plumes are observed within the boundary layer for the $50 \%$ of the cases examined. For the rest of the cases, the strong updrafts generated by the fires resulted to smoke injection heights greater than the ECMWF estimated mixing layer by 0.5 to $3.0 \mathrm{~km}$, indicating a direct smoke injection into the free troposphere. The smoke injec-
\end{abstract}

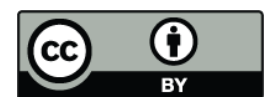

Correspondence to: V. Amiridis (vamoir@space.noa.gr) tion height showed a dependence on the MODIS-Land Fire Radiative Power product which is indicative of the fire intensity, especially in the cases of lower static stability in the upper part of the boundary layer and the free troposphere.

\section{Introduction}

Giglio et al. (2003), investigating the spatial and temporal occurrence of fires in croplands, based on the Moderate Resolution Imaging Spectroradiometer (MODIS) active fire product, showed that the Russian Federation was the largest contributor to agricultural burning globally during the period 2001 to 2003, producing 31-36\% of all agricultural fires. This globally highest concentration of agricultural fires, found to be extended across Russia in the latitudinal belt between $45^{\circ} \mathrm{N}-55^{\circ} \mathrm{N}$ during spring (April-May), as well as in Eastern Europe (Baltic countries, western Russia, Belarus, and the Ukraine) during late summer (end of July and August). Forest fires in this area are a major source of pollution in the Northern Hemisphere and especially Europe (Korontzi et al., 2006). Moreover, areas downwind of those fires (e.g. Eastern Mediterranean) are characterized by enhanced particulate loadings in the column but also at surface, especially during summer when meteorology favors the transport from northerly directions (e.g. Balis et al., 2003; Gerasopoulos et al., 2003; 2006; Amiridis et al., 2005, 2009; Fotiadi et al., 2006; Kazadzis et al., 2009; Zyrichidou et al., 2009), thus the need to model smoke transport and estimate its contribution to air quality degradation is important.

Smoke injection heights are key inputs for aerosol transport modeling, as they are critical for determining the

Published by Copernicus Publications on behalf of the European Geosciences Union. 
distance and direction of the travelling smoke (e.g., Colarco et al., 2004; Freitas et al., 2007). Biomass burning emits hot gases and particles, which are transported upward due to positive buoyancy. The interaction between the smoke and the environment produces eddies that entrain colder environmental air into the smoke plume, which dilutes the plume and reduces buoyancy. The final plume height is mostly controlled by the thermodynamic stability of the ambient atmosphere and the fire intensity. After this initial injection phase, the smoke enters the general atmospheric circulation. The fraction that is within the planetary boundary layer (PBL) height is well mixed by turbulent eddies and the particles experience more efficient removal processes than in the free troposphere (scavenging and wet-removal). On the other hand, the fraction of smoke that reaches the free troposphere is advected away faster from the source region while the residence time of the particles at these heights is increased. The described mechanism has a strong impact on pollutant dispersion, and as a consequence, the information of the initial injection height, and whether it appears inside the PBL or above, is a major parameter for a proper understanding and modeling of the atmospheric chemistry and transport of smoke (e.g. Freitas et al., 2007).

Recently, space-based observations of aerosols have been used for the estimation of smoke injection heights (Labonne et al., 2007; Kahn et al., 2007; Martin et al., 2009; Mims et al., 2010). Attenuated backscatter profiles derived by the Cloud-Aerosol Lidar with Orthogonal Polarization (CALIOP) on board the Cloud-Aerosol Lidar and Infrared Pathfinder Satellite Observations (CALIPSO) satellite (Winker et al., 2004, 2006, 2007) can be used to study the vertical structure of smoke aerosols and to define the smoke layer geometrical properties (e.g. Labonne et al., 2007; Dirksen et al., 2009). This type of information can be directly retrieved by the CALIPSO aerosol layer product which provides a description of the aerosol layers, including their top heights and bottoms. The injection heights of smoke plumes can be also analyzed using stereo-derived plume heights from the Multi-angle Imaging SpectroRadiometer (MISR; Diner et al., 1998), that flies aboard the NASA Earth Observing System's Terra satellite (Kahn et al., 2007; Martin et al., 2009; Mims et al., 2010). The spatial coverage of MISR's multi-angle imaging is vastly greater than that of the CALIPSO lidar, however, CALIPSO lidar is sensitive to the vertical distribution of dispersed aerosol away from sources, where MISR is not (Kahn et al., 2008; Martin et al., 2009; Mims et al., 2010).

In this paper we investigate the initial injection height of aerosol plumes generated by fires over SW Russia and Eastern Europe during the biomass burning season (July and August) for 2006, 2007 and 2008. To characterize typical injection heights of smoke over these regions we used the aerosol attenuated backscatter profile as this is derived with high vertical precision from CALIPSO space-borne lidar. Our approach on the extraction of injection heights from CALIPSO is based on detailed analysis of individual Level 1 raw lidar profiles. Moreover, MODIS and CALIPSO synergy is deployed to assess the fire intensity effect on smoke injection height. Added value is gained from the fact that both approaches are applied for the first time over a very significant area by means of biomass burning frequency and intensity, downwind of which severe air quality degradation is already encountered (e.g. Lelieveld et al., 2002). Finally, we attempted to assess the injection of smoke above the PBL by calculating the distribution of differences between aerosol injection height derived from CALIPSO, and PBL height obtained from the European Centre for Medium-range Weather Forecasts (ECMWF).

\section{Data and methodology}

\subsection{MODIS Active Fire}

For the identification of the areas that are affected by biomass burning over Western Russia and Eastern Europe during the biomass burning season, the MODIS active fire product (Giglio et al., 2003) has been used. The MODIS sensor is a multi-spectral sensor with 36 spectral bands, ranging in wavelength from 0.4 to $14.2 \mu \mathrm{m}$, and fires are detected at $1-\mathrm{km}$ spatial resolution (at nadir) using radiance measurements in the $4 \mu \mathrm{m}$ and $11 \mu \mathrm{m}$ channels. Measurements at several spectral bands are utilized for masking clouds, extremely bright surfaces, glint, and other potential sources of false alarms (Giglio et al., 2003). In the operational MODIS algorithm, only the $4 \mu \mathrm{m}$ channel measurements are used to calculate the Fire Radiative Power (FRP), based on the measured brightness temperatures of the fire pixel and its neighboring surface background. There are two 4- $\mu \mathrm{m}$ channels on each MODIS sensor, one of which is a "low-gain" channel that can record pixel-integrated brightness temperatures of up to $\sim 500 \mathrm{~K}$, thereby allowing unsaturated measurements to be made over even very large/most intensely burning wildfires. MODIS is a twin sensor flying on two NASA Earth Observing System (EOS) satellites: Terra (launched 19 December 1999) and Aqua (launched 4 May 2002). They are both polar orbiting, with Terra crossing the equator at approximately 10:30 a.m. and 10:30 p.m. local time, and Aqua at approximately 1:30 a.m. and 1:30 p.m. local time. Each MODIS sensor achieves near-global coverage once per day and once per night every $24 \mathrm{~h}$, with higher latitude locations observed slightly more frequently because of increasingly large overlaps from successive satellite passes. Therefore, most fires detectable at a $1-\mathrm{km}$ spatial resolution have the potential to have their FRP measured four times a day, except when covered by thick meteorological cloud. MODIS algorithms (including the fire algorithm) are updated periodically, leading to different versions, which are used to generate a series of Collections of the data products. The latest "Collection 5" fire data were used in this study. 


\subsection{CALIPSO}

The Cloud-Aerosol Lidar and Infrared Pathfinder Satellite Observation (CALIPSO) mission is a collaborative effort between the NASA Langley Research Center (LaRC), the Centre National D'Etudes Spatiales (CNES), Hampton University (HU), the Institut Pierre Simon Laplace (IPSL), and Ball Aerospace and Technologies Corporation (BATC) to study global radiative effects of aerosols and clouds on climate. CALIPSO is an Earth Science observation mission that was launched on 28 April 2006 and flies in nominal orbital altitude of $705 \mathrm{~km}$ and an inclination of 98 degrees as part of a constellation of Earth-observing satellites including Aqua, PARASOL, and Aura - collectively known as the "A-train". The CALIPSO mission provides crucial lidar and passive sensors to obtain unique data on aerosol and cloud vertical structure and optical properties (Winker et al., 2007).

CALIPSO's lidar, the Cloud-Aerosol Lidar with Orthogonal Polarization (CALIOP), is an elastically backscattered lidar operating at 532 and $1064 \mathrm{~nm}$, equipped with a depolarization channel at $532 \mathrm{~nm}$ that provides high-resolution vertical profiles of aerosols and clouds. The lasers operate at $20.16 \mathrm{~Hz}$ and are Q-switched to provide a pulse length of about $20 \mathrm{~ns}$. Each laser generates nominally $220 \mathrm{~mJ}$ per pulse at $1064 \mathrm{~nm}$, which is frequency-doubled to produce about $110 \mathrm{~mJ}$ of pulse energy at each of the two wavelengths. Beam expanders reduce the angular divergence of the transmitted laser beam to produce a beam diameter of $70 \mathrm{~m}$ at the Earth's surface (corresponding to a nominal laser beam divergence of $100 \mu \mathrm{rad}$ ) (Winker et al., 2004, 2006, 2007).

Level 1 scientific data products derived from raw CALIOP lidar measurements are archived and distributed by the Atmospheric Science Data Center (ASDC) of NASA (http: //eosweb.larc.nasa.gov/). The Level 1 data include: lidar calibrated and geolocated profiles with associated browse imagery with horizontal resolutions of $1 / 3 \mathrm{~km}, 1 \mathrm{~km}$ and $5 \mathrm{~km}$, an aerosol layer product at $5 \mathrm{~km}$ resolution (height, thickness, optical depth, and integrated attenuated backscatter), and an aerosol profile product with a horizontal resolution of $40 \mathrm{~km}$ and vertical resolution of $120 \mathrm{~m}$ (backscatter, extinction, and depolarization ratio). The CALIPSO Level-2 aerosol layer product provides a description of the aerosol layers, including their top heights and bottoms, identified by the use of automated algorithms from the Level-1 data. Detailed description of the abovementioned algorithms is given in Vaugan et al. (2004) and Winker et al. (2009). In our study, Level 1 CALIPSO products have been used.

\subsection{ECMWF Mixing Layer Height}

Mixing layer height analyses were retrieved from the ECMWF model that provides a diagnostic of the boundary layer height with a 12-hourly and $0.25^{\circ} \times 0.25^{\circ}$ latitudelongitude resolution. The height of the model topography is added to the grid-point values in order to make them compa- rable to the satellite data that provide heights above sea-level. The boundary layer height at a specific location is calculated through bilinear interpolation, using the weighted values of the four surrounding grid-points. As expected, the 12-hourly fields show a strong diurnal cycle with low values at night.

The parameterization of the mixed layer (and entrainment) in the deterministic atmospheric model of ECMWF uses a boundary layer height from an entraining parcel model (ECMWF, 2009b). The bulk Richardson method (Troen and Mahrt, 1986) is used as a diagnostic parameterization in order to get a continuous field in neutral and stable conditions. The boundary layer height is the level where the bulk Richardson number, based on the properties of that level and the lowest model level, reaches the critical value of 0.25 . If it is found to be between two model levels, the exact height is calculated through linear interpolation. It is noted that during the period of interest (2006-2008) the ECMWF model used 91 vertical levels up to $0.01 \mathrm{hPa}$, with a high vertical resolution in the boundary layer (approximately 14 hybrid levels in the lowest $150 \mathrm{hPa}$ ).

The boundary layer height analyses of the operational early-delivery assimilation system of ECMWF are utilized in this study. This system consists of two 6-h 4D-Var analysis cycles, at 00:00 and 12:00 UTC. The 0000 UTC (12:00 UTC) cycle uses observations from the time window 21:01-03:00 UTC (09:01-15:00 UTC) and a first guess forecast from the 12:00 UTC (00:00 UTC) delayed-cut-off 12hour 4D-Var analysis of the previous (same) day (Haseler 2004). The deterministic and ensemble prediction forecasts of ECMWF are initialized from the analyses of the early-delivery system (Persson and Grazzini, 2005). Haseler (2004) showed that the quality of the two first guesses is sufficiently high to allow the functioning of the abovementioned operational assimilation system without compromising the quality of the model forecasts.

A very large amount of observations from various sources is introduced in the data assimilation system. Typically, before the quality control there is a total of 75 million pieces of data available worldwide, around $98 \%$ from satellites, in a 12-h period (Persson and Grazzini, 2005). These data are divided into surface observations, upper-air observations from radiosondes and aircrafts, and satellite observations (mainly radiances) (ECMWF, 2009a).

\section{Results and discussion}

\subsection{Description of fires and prevailing meteorological conditions}

For the detection of fires for the fire season periods (July and August) between 2006 and 2008, the MODIS fire product over a grid extended to the longitudinal belt between $25^{\circ}$ to $45^{\circ} \mathrm{E}$, and the latitudinal belt between $40^{\circ}$ to $60^{\circ} \mathrm{N}$, has been used. Amiridis et al. (2009), used a global land 


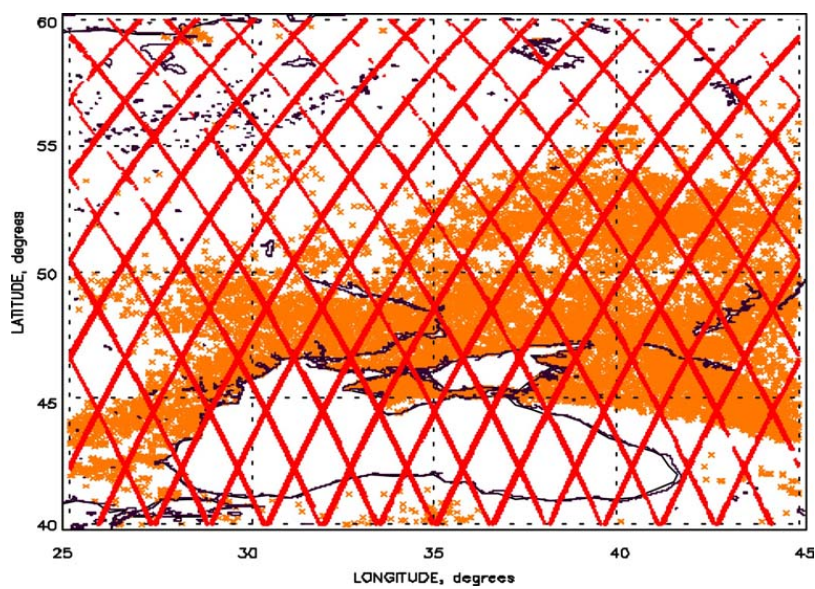

Fig. 1. Active fires as seen by MODIS during July and August 2006, 2007, 2008 for the Western Russian and Eastern Europe area. CALIPSO overpasses during the same time period are superimposed.

cover classification with a resolution of $300 \mathrm{~m}$ to show that the detected fires in the area of the abovementioned grid are mainly associated with agricultural burning activities. The locations of the active fires identified from MODIS observations are presented in Fig. 1. For the same period, the CALIPSO overpasses are superimposed. From the analysis of the MODIS FRP product, the overall minimum and maximum values of the FRP per pixel $(1 \times 1-\mathrm{km})$ detected by the sensor for the period under study, ranged between 6 to $80 \mathrm{MW} / \mathrm{km}^{2}$ with a mean value of $20 \pm 10 \mathrm{MW} / \mathrm{km}^{2}$. FRP values reported here refer to fires with MODIS fire detection confidence greater than $80 \%$. The detection confidence, which varies between 0 and $100 \%$, is a heuristic measure of the radiometric contrast between a fire pixel and its immediate non-fire neighborhood, with extra penalties imposed near potential false alarm sources such as cloud edges and coastline (Giglio et al., 2003).

The fires presented in this paper are of agricultural nature, and thus common practices are followed by the farmers including the fact that no fires are lit in times of strong or gusty winds. These measures are applied to control the lighting of the fires, as the fire danger is high during the summer fire season and may result to uncontrolled situations, especially during unsettled weather conditions. For the fires detected in the study area (Fig. 1), the above is further supported by the respective ECMWF wind speed data (Fig. 2a). The average wind speed at $10 \mathrm{~m}$ above the surface is found equal to $3.5 \pm 1.9 \mathrm{~m} / \mathrm{s}$, varying from 0.1 to $8.6 \mathrm{~m} / \mathrm{s}$, with $82 \%$ of the values below $5 \mathrm{~m} / \mathrm{s}$. These data indicate weak horizontal winds resulting in relatively slow advection of smoke plumes. From the analysis of the CALIPSO aerosol vertical profiles, no significant vertical variability is observed in most of the cases (see for example Fig. 3), indicating strong convection over the fire pixel and homogeneous smoke concen-
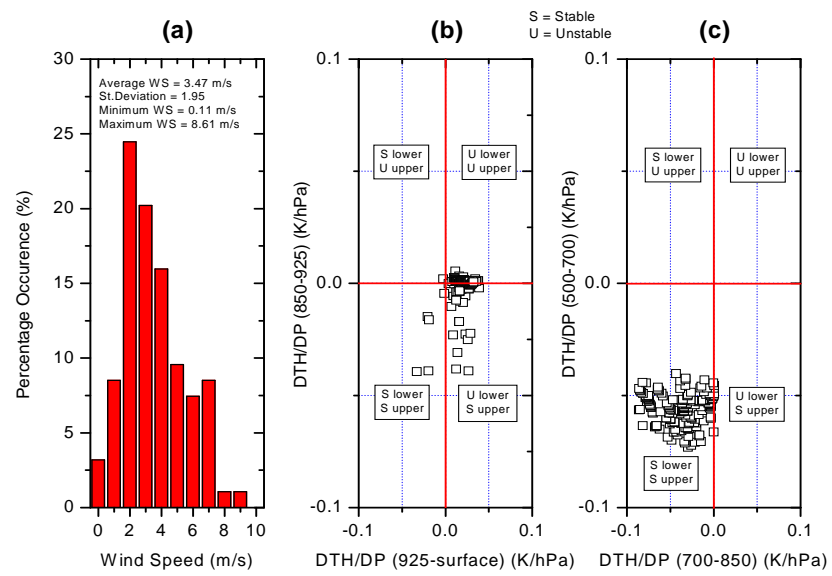

Fig. 2. (a) Frequency distribution of ECMWF wind speed analyses at $10 \mathrm{~m}$ above surface for the times and locations of fires under study over the Western Russian and Eastern Europe during July and August 2006, 2007, 2008. (b) Static stability of the layer $850-925 \mathrm{hPa}$, with the use of the ECMWF derived vertical gradient $\partial \theta / \partial p$ (where $\theta$ is the potential temperature and $p$ the pressure), versus the one of the lowest layer 925-surface, during the fire cases. (c) Static stability of the layer $500-700 \mathrm{hPa}$, with the use of the ECMWF derived vertical gradient $\partial \theta / \partial p$, versus the one of the lowest layer $700-850 \mathrm{hPa}$, during the fire cases.

trations with height. Thus, in our case it may be assumed that horizontal advection poses no or slight impact to the height that the smoke is injected in to the atmosphere. However, the possibility of smoke advection over the studied pixel from nearby fire sources cannot be neglected. An additional factor controlling the smoke convection is the atmospheric stability (e.g. Val Martin et al., 2010). In Fig. 2b, the static stability of the layer $850-925 \mathrm{hPa}$, with the use of the ECMWF derived vertical gradient $\partial \theta / \partial p$ (where $\theta$ is the potential temperature andp the pressure), versus the one of the lowest layer 925surface, during the fire cases, is illustrated. Negative values of $\partial \theta / \partial p$ indicate stability. The vast majority of the cases are associated with an unstable lower layer $(925 \mathrm{hPa}$ - surface probably due to the fact that 12 UTC analyses were utilized) and a nearly neutral upper layer $(850-925 \mathrm{hPa})$. The rest of the cases are associated with stable conditions in the layer between 925 and $850 \mathrm{hPa}$. Overall, mostly unstable conditions were encountered over the fire pixels, especially in the lower layer. In Fig. 2c, the potential temperature lapse rate of the layer $500-700 \mathrm{hPa}$ versus the lowest layer $700-850 \mathrm{hPa}$ is additionally illustrated to demonstrate the static stability conditions at higher levels, from the upper part of the boundary layer to the lower free troposphere. Most of the cases are associated with stability in both layers. The lapse rate in the layer $500-700 \mathrm{hPa}$ shows small variability, in the range between -0.075 and $-0.04 \mathrm{~K} / \mathrm{hPa}$. The layer $750-850 \mathrm{hPa}$ is also stable but with larger lapse rate variability, in the range between $0 \mathrm{~K} / \mathrm{hPa}$ to $-0.09 \mathrm{~K} / \mathrm{hPa}$. The atmospheric stability structure presented in Fig. 2 is considered in Sect. 3.3 to 


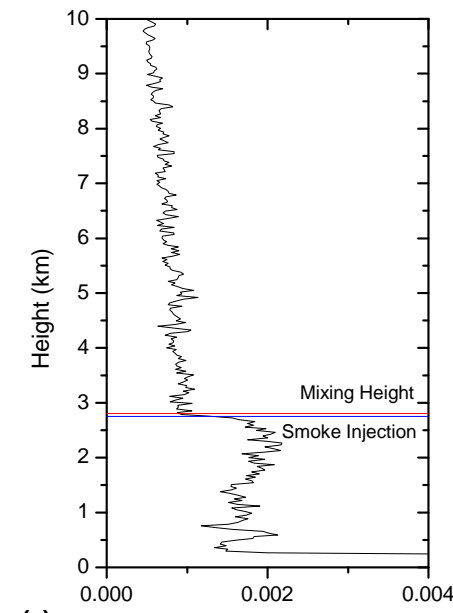

(a)

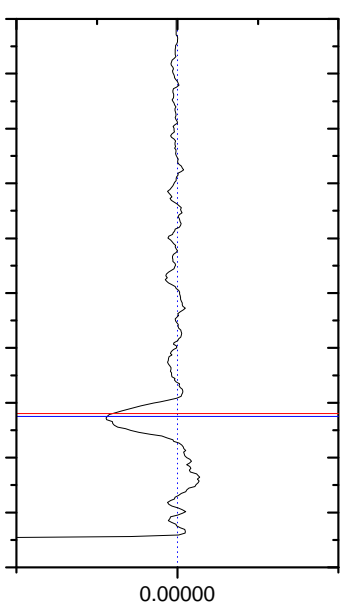

First Derivative of Total Attenuated Backscatter (AU)
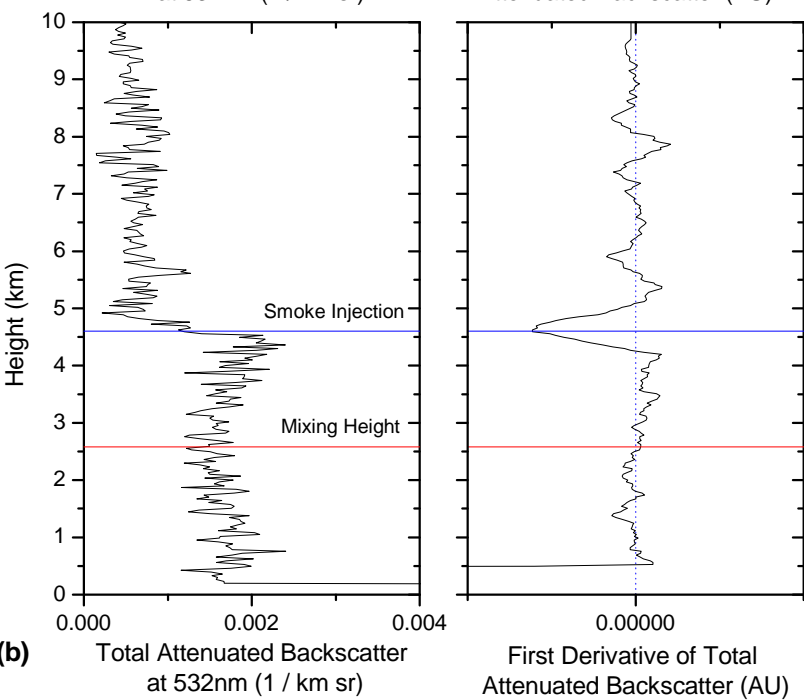

Fig. 3. Examples of CALIPSO Level-1 attenuated backscatter profiles at $532 \mathrm{~nm}$ and the corresponding injection heights (blue lines) calculated with the slope method (left panels) and the profiles of the corresponding first derivative of the attenuated backscatter coefficient (right panels) at 15 August 2006 (upper panels) and 16 August 2008 (lower panels). The ECMWF mixing heights are superimposed (red lines) to demonstrate that the smoke can lie within PBL (Fig. 3a), but also penetrate to the free troposphere (Fig. 2b).

assess the relationship between the smoke injection height and the fire power.

\subsection{CALIPSO retrieval of smoke injection height}

The detection of the mixing layer on CALIPSO's attenuated backscatter lidar profile is not easy to implement and can be associated with considerable errors, e.g., if the signal intensity is low and large statistical fluctuations cause sharp gradients in the profile. Such an algorithm requires the definition of threshold values (see Winker et al., 2009) and the results also depend on data averaging and spatial resolution of the range-corrected signals. For the needs of the current study, smoke injection heights are directly calculated from Level 1 attenuated backscatter profiles at $532 \mathrm{~nm}$ by applying a slope method (Pal et al., 1992) on each individual profile. Following this approach, we are able to separate the cases of strong aerosol convection, by selecting only the lidar profiles of constant attenuated backscatter coefficient with height. Moreover, by using Level 1 CALIPSO products we are able to apply spatial averaging of the lidar profiles within the MODIS pixel, to appropriately collocate CALIPSO and MODIS data. This is not feasible with Level 2 products, since, the aerosol layer heights are provided with a fixed spatial resolution of $5 \mathrm{~km}$ along the path of the satellite. In the application of the slope method to the averaged attenuated backscatter coefficient profile, the steep gradient in the attenuated backscatter signal has been identified in the lidar profiles, and the height of the minimum gradient value has been selected as the smoke injection height. The minimum of the gradient is due to the high decrease in the attenuated aerosol backscatter caused by lower particle concentration above the smoke layer. The method is very simple and it has been used for the calculation of the mixing height in previous works (Flamant et al., 1997; Menut et al., 1999). It is also been validated against independent methods to derive the mixing height (e.g. Kaimal et al., 1982) showing good agreement under well mixed conditions.

Time coincidence of CALIPSO and MODIS data is only possible for the MODIS instrument aboard Aqua satellite, since in that case the time difference between the overpasses is of the order of $75 \mathrm{~s}$, with Aqua preceding the CALIPSO satellite. CALIPSO shots are then averaged within the MODIS pixel to produce the MODIS-collocated lidar profile. The averaged profile can be very noisy, especially during daytime acquisitions, allowing only poor retrievals of layer products using the slope method. While high signal to noise ratio (SNR) is required for the slope method to function properly, CALIPSO's orbital velocity of $\sim 7 \mathrm{~km} / \mathrm{s}$, combined with the need to retrieve feature boundaries of the aerosol layers at high vertical and horizontal resolutions, allows only minimal spatial averaging. To overcome SNR constrains, a 5$\mathrm{km}$ spatial averaging centered on the MODIS $(1 \times 1 \mathrm{~km})$ fire pixel has been applied in addition to vertical moving average with a window frame of $400 \mathrm{~m}$. Following our approach, the collocation could be highly inaccurate under these assumptions, giving false results when MODIS products are compared with CALIPSO ones. However, no significant changes have been found on the shape of aerosol layers between the correctly collocated approximately 1-km horizontally averaged CALIPSO profiles used in this study and the $5-\mathrm{km}$ Level-2 product that includes the MODIS pixel. This can be attributed to the possible horizontal distribution of smoke around the fire pixel for our cases, or to the existence of fire pixels in an area extended in the neighbour of the fire pixel under study, resulting in dispersed smoke in a wider area over the CALIPSO overpass. 


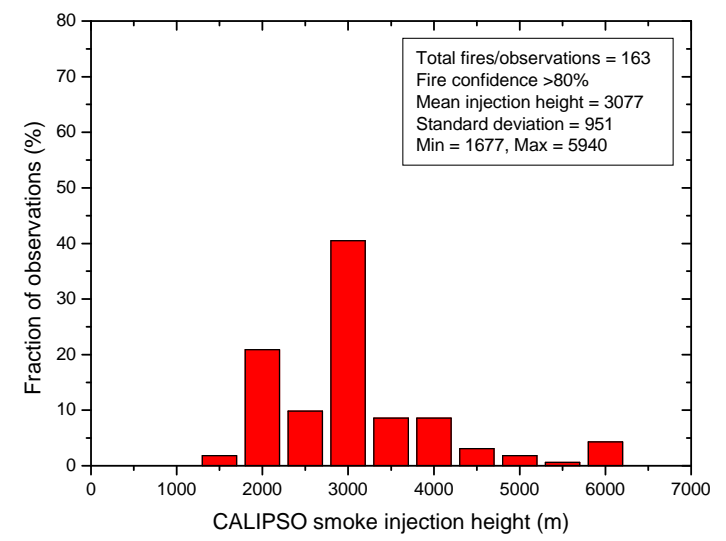

Fig. 4. Frequency distribution of the aerosol top height binned in $500 \mathrm{~m}$ height intervals, as retrieved by CALIPSO over the Western Russian and Eastern Europe during July and August 2006, 2007, 2008.

To demonstrate the methodology followed for the calculation of the injection height, we present two examples from our dataset in Fig. 3. In both examples, the vertical profiles of the CALIPSO attenuated backscatter coefficient at 532 $\mathrm{nm}$ (horizontally averaged at $1 \mathrm{~km}$ and vertically smoothed at $400 \mathrm{~m}$ ), centered in the MODIS pixel are presented. In the first case of 15 August 2006 (Fig. 3a), following the slope method, a minimum of the derivative (right panel) is found at $2700 \mathrm{~m}$. This height is considered as the smoke injection height for the fire pixels detected by MODIS. The ECMWF mixing height for the pixel under study is superimposed, showing that the smoke is injected within the PBL. An example of much higher injection height is presented in Fig. 3b (16 August 2008). The slope method (right panel) delivers a derivative minimum at the height of $4540 \mathrm{~m}$, which lies well above the PBL, in the free troposphere. In both cases, a vertically homogeneous distribution of smoke is indicated by the CALIPSO profiles.

After the calculation of the aerosol top height from CALIPSO's profiles with the slope method, for a total of 163 fire hot spots detected by MODIS (fire confidence greater than $80 \%$ ), we found that the smoke injection height ranged between $1677 \mathrm{~m}$ and $5940 \mathrm{~m}$ above sea level, having a mean value of $3077 \pm 951 \mathrm{~m}$. The frequency distribution for our dataset, binned in $500 \mathrm{~m}$ height intervals is presented in Fig. 4. Labonne et al. (2007), using CALIPSO data for summer 2006 over Eastern Europe found a similar range for the top height of the aerosol layers, ranging from 1.5 to $6 \mathrm{~km}$. This range is the largest globally, as reported in this study.

\subsection{Smoke injection in respect to mixing height, fire intensity and stability}

To identify the cases of smoke injection within or above PBL, we compare the CALIPSO aerosol injection heights with the Boundary Layer Height (BLH) from the ECMWF model.
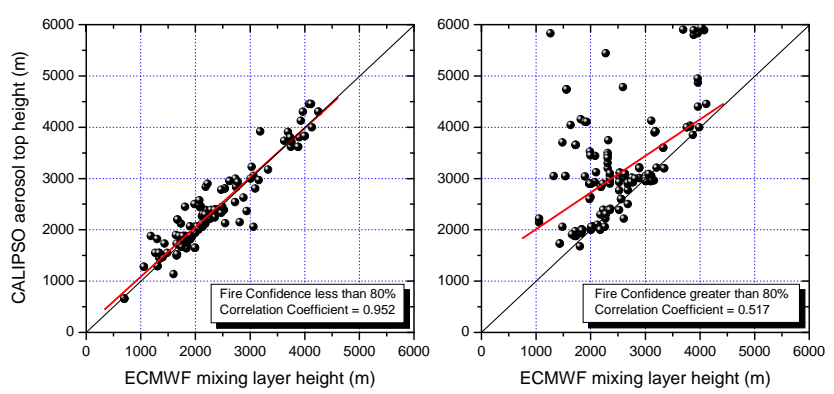

Fig. 5. Comparison of aerosol top height derived by CALIPSO with mixing layer height from ECMWF model for fire confidence less than $80 \%$ (left panel) and greater than $80 \%$ (right panel).

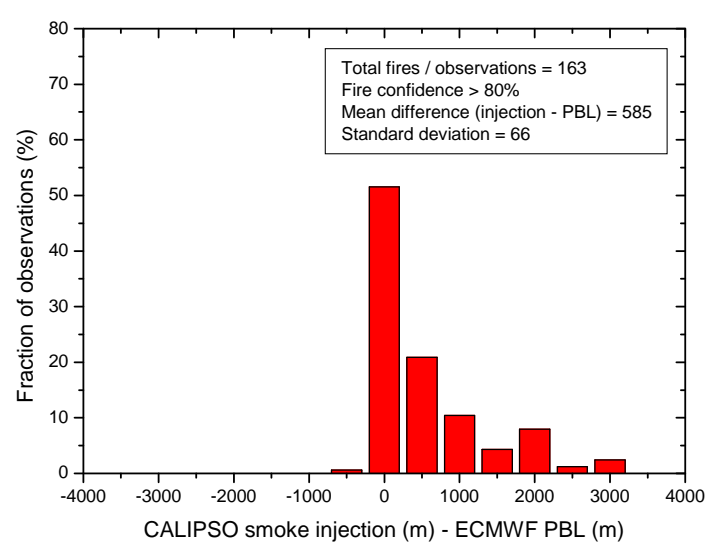

Fig. 6. Frequency distribution of the differences between CALIPSO derived smoke injection height and ECMWF's mixing layer height for the cases with fire confidence greater than $80 \%$.

The BLH field in the ECMWF data corresponds to the height above topography. The injection heights from CALIPSO used for this comparison are corrected to refer to the surface elevation instead of sea level, for consistency with ECMWF data. This correction could be significant in case of profound orography. However, and as stated before for the comparison between the injection height and the FRP, the exact surface elevation levels of the points included in Fig. 6 vary between 0 and $196 \mathrm{~m}$ (mean $=125 \mathrm{~m}$, standard deviation $=65$ $\mathrm{m})$, and this is rational since we are dealing with agricultural fires initiated in crop fields which are mostly located at non-elevated terrains. Our final corrected data with respect to the surface for the studied area and for the fire seasons of the years between 2006 to 2008, are presented in Fig. 5. In both panels of Fig. 5, near-synchronous ECMWF/CALIPSO measurements are selected. The overpass times of CALIOP and MODIS instruments over the area of study (due to orbit adjustments and geographical area extent) varies between 10:00 and 10:26 UTC for CALIOP/CALIPSO and 10:30 and 10:55 UTC for MODIS/AQUA. According to the abovementioned times, the time difference between the pairs of satellite/model data used in our comparisons, taking into account 
the use of 12:00 UTC ECMWF analysis data ranges between $1 \mathrm{~h} / 5 \mathrm{~min}$ and $2 \mathrm{~h}$. The only analyses ECMWF BLH fields are from 00:00 and 12:00 UTC. Hence the ECMWF data used for this study refer only to the analyses fields for BLH at 12:00 UTC, which is the closest in time available analyses BLH data to the overpasses. All the other ECMWF products for BLH refer to forecasted fields which are not used in this study. However, a possible bias in our comparison could be introduced by the fact that CALIPSO/MODIS overpass is always earlier than 12:00 UTC, and that the boundary layer height is usually still growing from 10:00 to 12:00 UTC.

In the left panel of Fig. 5, all the near-synchronous (12:00 UTC) CALIPSO aerosol top heights and ECMWF mixing layer heights are presented, showing a very good agreement when the MODIS fire confidence is less than $80 \%$ (correlation coefficient equal to 0.952). The "fire confidence" MODIS product is a measure representing the level of confidence that the observation is indeed a "true" fire (ranging from 0-100\%). Following the user guide for MODIS fire products, the users requiring fewer false alarms, may wish to consider only high-confidence (greater that $80 \%$ ) and treat low-confidence fire pixels (less than 80\%) as clear, non-fire, land pixels. Considering this statement, the data on the left panel of Fig. 5 are most likely referring to non-fire pixels, showing that in these cases ECMWF BLH heights are in good agreement with CALIPSO derived heights of the top of the aerosol layer. This indicates that the CALIPSO retrievals are in good agreement with ECMWF BLH for no fire incidents.

For the fire cases examined here, where MODIS fire confidence is greater than $80 \%$ (Fig. 5, right panel), the correlation coefficient drops to 0.517 . This may have several plausible reasons listed below:

(a) In the presence of strong fire activity the smoke particles can be directly injected well above the PBL height into the free troposphere, and this could be a possible explanation of the greater values of CALIPSO's aerosol top heights compared with those of ECMWF's mixing heights.

(b) The strong fire activity may increase the thermal instability of the ambient lower atmosphere thus inducing an increase of the PBL height, a fact which is not captured by the ECMWF model. This can be due to the fact that the assimilation of the ECMWF model does not take into account the strong updrafts generated by the fires for the calculation of the mixing height.

(c) It could be a combination of both previous explanations.

In Fig. 6, the frequency distribution of the differences between the CALIPSO aerosol top height and ECMWF's estimated mixing height is presented. It is evident that for the 163 cases of the fires examined here, the $51.5 \%$ of the cases were found to lie within the PBL. For the $48.5 \%$ of the cases examined, the smoke has been injected directly into the free troposphere. The smoke reached heights above the mixing layer in the order of $0.5 \mathrm{~km}$ for $20.8 \%$ of the cases, $1 \mathrm{~km}$ for $10.4 \%$ of the cases and between 1.5 and even $3.0 \mathrm{~km}$ for $17.3 \%$ of the cases. In their study for the year 2006, Labonne et al. (2007), reported that the smoke from the fires in Eastern Europe is often contained within the mixing layer, but the authors report also a large number of cases where the smoke extends well above the ECMWF diagnosed top height. Direct injection of smoke in high free-tropospheric altitudes has been also reported in the past for biomass burning events in mid and high latitudes (Fromm et al., 1998; Jost et al., 2004).

Taking into account the large range of injection heights for the studied area, we have tried to further investigate the relation between the fire intensity and the injection height. The injection heights from CALIPSO used for this comparison are corrected to refer to the surface elevation instead of sea level, for consistency with MODIS FRPs which refer to surface fires. This correction could be significant in case of profound orography. However, the exact surface elevation levels for the fire pixels under study, taken by the Digital Elevation Model used by CALIPSO at the lidar footprint (GTOPO30 digital elevation map), vary between 0 and 196 $\mathrm{m}($ mean $=125 \mathrm{~m}$, standard deviation $=65 \mathrm{~m})$, and this is rational since we are dealing with agricultural fires initiated in crop fields which are mostly located at non-elevated terrains. Disregarding horizontal transport processes but also the vertical thermal profile of the lower atmosphere (boundary layer and the lower free troposphere), one would expect that the main driver of the fire smoke would be the convection by the fire heat, and thus, higher values of injection heights should be expected for higher FRPs.

In Fig. $7 \mathrm{a}$, the scatter plot between FRP and injection height is shown in log-log scale, revealing enhanced dispersion of the values. However, an increasing tendency of injection height with FRP is evident. The regression line in the log-log plot revealed a slope of 0.39 and an intercept of 2.94. These results are comparable with the range of the respective values given by Val Martin et al. (2010) for North America and for different atmospheric stability setups. A more detailed comparison with these findings is not meaningful since our study area is located in a lower latitudinal belt with different PBL characteristics and different biomes. Moreover, that paper deals with wild fires of a wide range of fire intensity instead of the narrow FRP range of the controlled agricultural fires studied here.

Overall, the scatter in Fig. 7a is indicative of the fact that many factors other than the FRP are responsible for the high dispersion of the values. In particular, the data scatter could be partly attributed to the fact that the smoke plumes from neighboring fire pixels are probably influencing injection height retrievals at downwind pixels under study. Moreover, the possible presence of dense smoke above the fire area (smoldering versus flaming fires) may lead to underestimates of the FRP values from MODIS due to the emissivity 

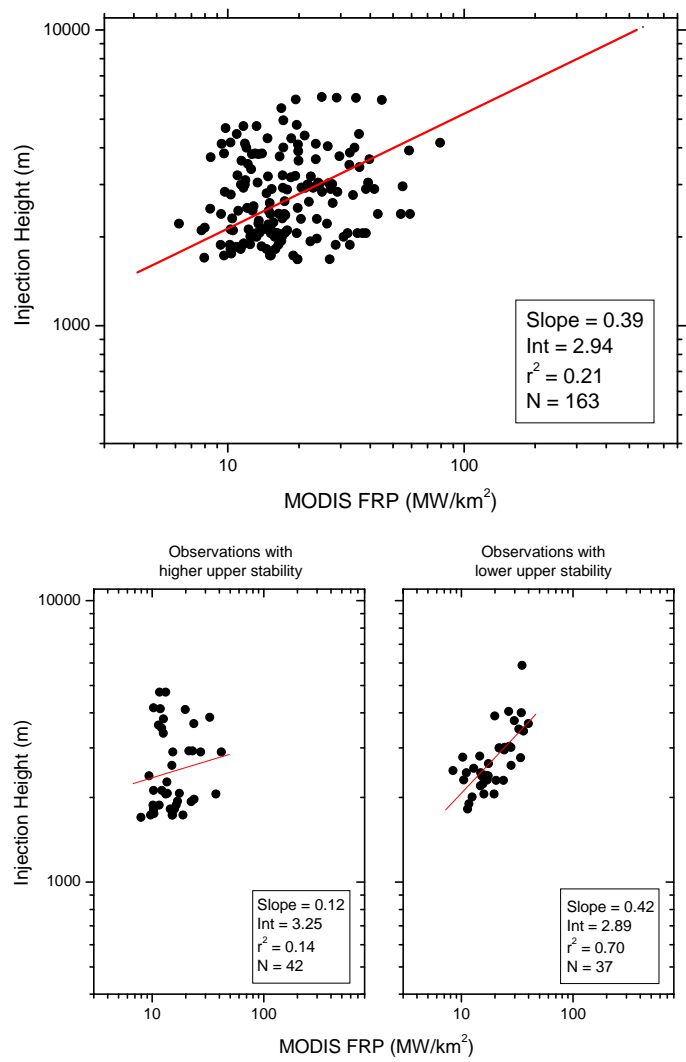

(a)

Fig. 7. (a) Log-log scatter-plot of Fire Power versus smoke Injection Height. The continuous red line is the regression line of the data set. (b) Log-log scatter-plot of Fire Power versus smoke Injection Height in the case of the presence of stable layers in the free troposphere (left panel) and when the free troposphere showed almost neutral atmospheric stability conditions (right panel).

assumed in the retrieval (Kahn et al., 2007). Finally the physical processes including the atmospheric static stability, the vertical wind shears and the horizontal advection, are expected to play an important role adding to the parameters driving the smoke injection. The above mentioned physical processes are further investigated to explore the large scatter of Fig. 7a.

As far as it concerns the role of the vertical wind shear, it is expected to be stronger in the lower part of the boundary layer or at the transition zone from the boundary layer to the free troposphere. The calculation of the vertical wind shear at the lowest 4 layers (surface- $925 \mathrm{hPa}, 925-850 \mathrm{hPa}, 850$ $700 \mathrm{hPa}$ and $700-500 \mathrm{hPa}$ ), based on the low vertical resolution of the standard pressure levels of the ECMWF model, did not provide a reasonable mean to explore the large scatter of Fig. 7a (results not shown) in our selected cases. As far as it concerns the role of the horizontal advection it should be noted that the ECMWF data for the selected cases indicate weak horizontal winds resulting in relatively slow advection of smoke plumes (see Sect. 3.1 and Fig. 2a).
Finally, concerning the role of the static stability, we tried to additionally classify our results by the potential temperature lapse rate at levels above the PBL (shown in Fig. 2c), where the atmospheric stability is considered to play a critical role for the plume rise. A similar approach was followed by Val Martin et al. (2010), who considered the depth of the stable layer to be the difference between the height of the top of the stable layer and the height of the bottom of the stable layer, using the meteorological data assimilation scheme from the GEOS model with 5 levels (in the vertical) between about $850 \mathrm{hPa}$ to $500 \mathrm{hPa}$. In our case, we have used the standard pressure levels of the ECMWF model with practically only 3 levels between about $850 \mathrm{hPa}$ to $500 \mathrm{hPa}(850$, 700 and 500). Specifically, we have calculated the potential temperature lapse rate $(d \Theta / d P)$ in the layers between $850-700 \mathrm{hPa}$ and $700-500 \mathrm{hPa}$. The data used for this investigation refer to injection heights above the $\mathrm{PBL}$ as this was diagnosed by ECMWF, which, following Fig. 6, are the $48.5 \%$ of the total of the 163 cases examined. In Fig. $7 \mathrm{~b}$, two scatter plots between the FRP and the injection height are shown in log-log scale; the left panel corresponding to more stable conditions and the right panel to less stable conditions in the free troposphere. The threshold values adopted for the classification are the average values of the lapse rate for each corresponding layer, presented in Fig. 2c. In the left panel of Fig. 7b, the cases with stability greater than the average of both layers (for 700-850 hPa: $d \Theta / d P<-0.045$; for $500-700 \mathrm{hPa}: d \Theta / d P<-0.056$ ), are presented, indicating the presence of relatively stable layers in the free troposphere. In this case (Fig. $7 \mathrm{~b}$, left panel), the correlation between the injection height and the FRP is poor, since the smoke plumes are potentially limited by the elevated stable layers and thus, the vertical transport is less favored. In the right panel of Fig. $7 \mathrm{~b}$, the cases with stability less than the average of both layers (for 700-850 hPa: $d \Theta / d P>-0.045$; for 500-700 hPa: $d \Theta / d P>-0.056$ ), are presented, indicating the presence of relatively less stable to neutral layers in the free troposphere. These cases are considered more favorable for injection in the free troposphere, depending on the fire characteristics and thus, are expected to better correlate with the FRP. Indeed, the explained variance of the relation between plume injection height and FRP in the right panel of Fig. 7b improves considerably, reaching 70\%. Conclusively, the lower stability in the upper part of the boundary layer and the free troposphere favors the better relation between plume injection height and FRP.

\section{Summary and conclusions}

The initial injection height of smoke aerosol generated by fires over SW Russia and Eastern Europe during the biomass burning season, for the years between 2006 and 2008 , has been investigated using the synergy of CALIPSO and MODIS satellite sensors. CALIPSO derived injection 
heights for the location of fires (pointed by MODIS fire products) found to be extremely variable, ranging from 1.6 and $5.9 \mathrm{~km}$ for the area of our interest. For the comparison of the smoke injection height with the mixing layer thickness, ECMWF model estimations of the mixing layer height have been used for the hot spots analyzed in this paper. For the cases of fires with high confidence (fire confidences greater that $80 \%$ according to MODIS) data support that biomass burning plumes are by $50 \%$ injected within the mixing layer (as diagnosed by the ECMWF short-range forecast), and by $50 \%$ penetrate in the free troposphere. However, the atmospheric transport of smoke from neighboring or distant sources cannot be evaluated using just CALIPSO data, although we chose to show only cases with vertical aerosol homogeneity, indicative of strong convection above the fire locations. Injection heights examined showed a tendency to increase with increased FRP MODIS product which is indicative of the fire intensity. This relation improves especially for cases with lower stability in the upper part of the boundary layer and the free troposphere.

Future work including the synergy of CALIPSO and MISR sensors could be a potential method for most accurate geometrical characterization of smoke plumes and more accurate attribution of the smoke plume to the corresponding source. Additional modeling tools for atmospheric transport calculations, including moist convection, can be synergistically used to provide parameterizations of biomass burning plumes in general circulation models.

Acknowledgements. The research work was financially supported by the European Commission's research project: Monitoring Atmospheric Composition and Climate (MACC) - Grant agreement no.: 218793, 7th Framework Programme - Theme 9: Space and by the EU-FP6 EARLINET-ASOS project (RICA-025991). The authors would like to thank the CALIPSO and MODIS NASA teams and ECMWF for giving us access to data products through their web ordering systems. SK would like to acknowledge Marie Curie project ACI-UV, PERG05-GA-2009-247492. Finally, the authors would like to thank the anonymous reviewers for their thorough review and suggestions, which significantly contributed to improve the quality of the publication.

Edited by: I. Aben

\section{References}

Amiridis, V., Balis, D. S., Kazadzis, S., Bais, A., Giannakaki, E., Papayannis, A., and Zerefos, C.: Four-year aerosol observations with a Raman lidar at Thessaloniki, Greece, in the framework of European Aerosol Research Lidar Network (EARLINET), J. Geophys. Res., 110, D21203, doi:10.1029/2005JD006190, 2005.

Amiridis, V., Balis, D. S., Giannakaki, E., Stohl, A., Kazadzis, S., Koukouli, M. E., and Zanis, P.: Optical characteristics of biomass burning aerosols over Southeastern Europe determined from UVRaman lidar measurements, Atmos. Chem. Phys., 9, 2431-2440, doi:10.5194/acp-9-2431-2009, 2009.
Balis, D., Amiridis, V., Zerefos, C., Gerasopoulos, E., Andreae, M. O., Zanis, P., Kazantzidis, A., Kazadzis, S., and Papayannis, A.: Raman lidar and sunphotometric measurements of aerosol optical properties over Thessaloniki, Greece, during a biomass burning episode, Atmos. Environ., 37(32), 4529-4538, 2003.

Colarco, P. R., Schoeberl, M. R., Doddridge, B. G., Marufu, L. T., Torres, O., and Welton, E. J.: Transport of smoke from Canadian forest fires to the surface near Washington, D. C.: Injection height, entrainment, and optical properties, J. Geophys. Res., 109, D06203, doi:10.1029/2003JD004248, 2004.

Diner, D. J., Beckert, J., Reilly, T., Bruegge, C., Conel, J., Kahn, R., Martonchik, J., Ackerman, T., Davies, R., Gerstl, S., Gordon, H., Muller, J.-P., Myneni, R., Sellers, P., Pinty, B., and Verstraete, M., Multi-angle Imaging SpectroRadiometer (MISR) instrument description and experiment overview, IEEE Trans. Geosci. Remote Sens., 36, 1072-1087, 1998.

Dirksen, R. J., Folkert Boersma, K., de Laat, J., Stammes, P., van der Werf, G. R., Val Martin, M., and Kelder, H. M.: An aerosol boomerang: Rapid around-the-world transport of smoke from the December 2006 Australian forest fires observed from space, J. Geophys. Res., 114, D21201, doi:10.1029/2009JD012360, 2009.

ECMWF: IFS Documentation - CY33r1. Part II: Data Assimilation. European Center for Medium-Range Weather Forecasts, Shinfield Park, Reading, UK, 160 pp., available online at: http://www.ecmwf.int/research/ifsdocs/CY33r1/ ASSIMILATION/IFSPart2.pdf, 2009a.

ECMWF: IFS Documentation - CY33r1. Part IV: Physical Processes. European Center for Medium-Range Weather Forecasts, Shinfield Park, Reading, UK, 162 pp., available online at: http://www.ecmwf.int/research/ifsdocs/CY33r1/PHYSICS/ IFSPart4.pdf) 2009b.

Flamant, C., Pelon, J., Flamant, P., and Durand, P.: Lidar determination of the entrainment zone thickness at the top of the unstable marine, atmospheric boundary layer, Bound. Layer Meteorol., 83, 247-284, 1997

Fotiadi, A., E. Drakakis, N. Hatzianastassiou, C. Matsoukas, K. G. Pavlakis, D. Hatzidimitriou, E. Gerasopoulos, N. Mihalopoulos, and I. Vardavas, Aerosol physical and optical properties in the eastern Mediterranean Basin, Crete, from Aerosol Robotic Network data, Atmos. Chem. Phys., 6, 5399-5413, doi:10.5194/acp6-5399-2006, 2006.

Freitas, S. R., Longo, K. M., Chatfield, R., Latham, D., Silva Dias, M. A. F., Andreae, M. O., Prins, E., Santos, J. C., Gielow, R., and Carvalho Jr., J. A.: Including the sub-grid scale plume rise of vegetation fires in low resolution atmospheric transport models, Atmos. Chem. Phys., 7, 3385-3398, doi:10.5194/acp-7-33852007, 2007.

Fromm, M., Alfred, J., Hoppel, K., Hornstein, J., Bevilacqua, R., Shettle, E., Servranckx, R., Li, Z., and Stocks, B.: Observations of boreal forest fire smoke in the stratosphere by POAM III, SAGE II, and lidar in 1998, Geophys. Res. Lett., 27, 14071410, 1998.

Gerasopoulos E., Andreae, M. O., Zerefos, C. S., Andreae, T. W., Balis, D., Formenti, P., Merlet, P., Amiridis, V., and Papastefanou, C.: Climatological aspects of aerosol optical properties in Northern Greece, Atmos. Chem. Phys., 3, 2025-2041, doi:10.5194/acp-3-2025-2003, 2003.

Gerasopoulos, E., Kouvarakis, G., Babasakalis, P., Vrekoussis, M., Putaud,J. P., and Mihalopoulos, N.: Origin and variability of 
particulate matter $\left(\mathrm{PM}_{10}\right)$ mass concentrations over the eastern Mediterranean, Atmos. Environ., 40, 4679-4690, 2006.

Giglio, L., Descloitres, J., Justice, C. O., and Kaufman, Y. J.: An enhanced contextual fire detection algorithm for MODIS, Remote Sens. Environ., 87, 273-282, doi:10.1016/S00344257(03)00184-6, 2003.

Haseler, J.: Early-delivery suite. ECMWF Newsletter No. 101, 2130, 2004.

Jost, H.-J., Drdla, K., Stohl, A., Pfister, L., Loewenstein, M., Lopez, J. P., Hudson, P. K., Murphy, D. M., Cziczo, D. J., Fromm, M., Bui, T. P., Dean-Day, J., Gerbig, C., Mahoney, M. J., Richard, E. C., Spichtinger, N., Pittman, J. V., Weinstock, E. M., Wilson, J. C., and Xueref, I.: In situ observations of mid-latitude forest fire plumes deep in the stratosphere, Geophys. Res. Lett., 31, L11101, doi:10.1029/2003GL019253, 2004

Kahn, R. A., Li, W.-H., Moroney, C., Diner, D. J., Martonchik, J. V., and Fishbein, E.: Aerosol source plume physical characteristics from space-based multi-angle imaging, J. Geophys. Res., 112, D11205, doi:10.1029/2006JD007647, 2007.

Kahn, R. A., Chen, Y., Nelson, D. L., Leung, F.-Y., Li, Q., Diner, D. J., and Logan, J. A.: Wildfire Smoke Injection Heights Two Perspectives from Space, Geophys. Res. Lett., 35, L04809, doi:10.1029/2007GL032165, 2008.

Kaimal, J. C., Abshire, N. L., Chadwick, R. B., Decker, M. T., Hooke, W. H., Kropfli, R. A., Neff, W. D., Pasqualucci, F., and Hildebrand, P. H.: Estimating the depth of the daytime convective boundary layer, J. Appl. Meteorol., 21, 1123-1129, 1982.

Kazadzis, S., Bais, A., Amiridis, V., Balis, D., Meleti, C., Kouremeti, N., Zerefos, C. S., Rapsomanikis, S., Petrakakis, M., Kelesis, A., Tzoumaka, P., and Kelektsoglou, K.: Nine years of UV aerosol optical depth measurements at Thessaloniki, Greece, Atmos. Chem. Phys., 7, 2091-2101, doi:10.5194/acp-7-20912007, 2007.

Korontzi, S., McCarty, J., Loboda, T., Kumar, S., and Justice, C. O.: Global distribution of agricultural fires in croplands from 3 years of Moderate Resolution Imaging Spectroradiometer (MODIS) data, Global Biogeochem. Cy., 20(2), GB2021, doi:10.1029/2005GB002529, 2006

Labonne, M., Breon, F.-M., and Chevallier, F.: Injection height of biomass burning aerosols as seen from a spaceborne lidar, Geophys. Res. Lett., 34, L11806, doi:10.1029/2007GL029311, 2007.

Lelieveld, J., Berresheim, H., Borrmann, S., Crutzen, P. J., Dentener, F. J., Fischer, H., Feichter, J., Flatau, P. J., Heland, J., Holzinger, R., Korrmann, R., Lawrence, M. G., Levin, Z., Markowicz, K. M., Mihalopoulos, N., Minikin, A., Ramanathan, V., de Reus, M., Roelofs, G. J., Scheeren, H. A., Sciare, J., Schlager, H., Schultz, M., Siegmund, P., Steil, B., Stephanou, E. G., Stier, P., Traub, M., Warneke, C., Williams, J., and Ziereis, H.: Global air pollution crossroads over the Mediterranean, Science, 298, 794-799, 2002.
Menut, L., Flamant, C., Pelon, J., and Flamant, P.: Urban boundary layer height determination from lidar measurements over the Paris area, Appl. Opt., 38, 945-954, 1999

Mims, S. R., Kahn, R. A., Moroney, C. M., Gaitley, B. J., Nelson, D. L., and Garay, M. J.: MISR Stereo Heights of Grassland Fire Smoke Plumes in Australia, IEEE Trans. Geosci. Remote Sens., 48, 25-35, No. 1, 2010.

Pal, S. R., Steinbrecht, W., and Carswell, A. I.: Automated method for lidar determination of cloud base height and vertical extent, Appl. Opt., 31, 1488-1494, 1992.

Persson A. and Grazzini, F.: User Guide to ECMWF forecast products. Meteorological Bulletin M3.2. European Center for Medium-Range Weather Forecasts, Shinfield Park, Reading, UK, 154, pp., 2005.

Troen, I. and Mahrt, L.: A simple model of the atmospheric boundary layer; sensitivity to surface evaporation, Bound.-Layer Meteorol., 37, 129-148, 1986.

Val Martin, M., Logan, J. A., Kahn, R. A., Leung, F.-Y., Nelson, D. L., and Diner,D. J.: Smoke injection heights from fires in North America: analysis of 5 years of satellite observations, Atmos. Chem. Phys., 10, 1491-1510, doi:10.5194/acp-10-14912010, 2010.

Vaughan, M. A., Young, S. A., Winker, D., Powell, K., Omar, A., Liu, Z., Hu, Y., and Hostetler, C.: Fully automated analysis of space-based lidar data: an overview of the CALIPSO retrieval algorithms and data products, Proc. SPIE, 5575, doi:10.1117/12.572024, 2004.

Winker, D., Hostetler, C., and Hunt, W., CALIOP: The CALIPSO Lidar, Proc. 22nd International Laser Radar Conference (ESASP 561), Matera, Italy, 941-944, 2004.

Winker, D., Vaughan, M., and Hunt, W.: The CALIPSO mission and initial results from CALIOP, Proc. SPIE, 6409, doi:10.1117/12.698003, 2006.

Winker D. M., Hunt, W. H., and McGill, M. J.: Initial performance assessment of CALIOP, Geophys. Res. Lett., 34, L19803, doi:10.1029/2007GL030135, 2007.

Winker, D., Vaughan, M., Omar, A., Hu, Y., Powell, K., Liu, Z., Hunt, and W., Young, S.: Overview of the CALIPSO Mission and CALIOP Data Processing Algorithms, J. Atmos. Ocean. Tech., 26, 2310-2323, 2009.

Zyrichidou, I., Koukouli, M. E., Balis, D. S., Katragkou, E., Melas, D., Poupkou, A., Kioutsioukis, I., van der A, R., Boersma, F. K., van Roozendael, M. and Richter, A.: Satellite observations and model simulations of tropospheric $\mathrm{NO}_{2}$ columns over south-eastern Europe, Atmos. Chem. Phys., 9, 6119-6134, doi:10.5194/acp-9-6119-2009, 2009. 